\title{
Frontières
}

\section{DASTUR, Françoise, Comment affronter la mort ?, Paris, Bayard, 2005, 96 p.}

\section{Jean-Jacques Lavoie}

Volume 18, numéro 2, printemps 2006

URI : https://id.erudit.org/iderudit/1073232ar

DOI : https://doi.org/10.7202/1073232ar

Aller au sommaire du numéro

Éditeur(s)

Université du Québec à Montréal

ISSN

1180-3479 (imprimé)

1916-0976 (numérique)

Découvrir la revue

Citer ce compte rendu

Lavoie, J.-J. (2006). Compte rendu de [DASTUR, Françoise, Comment affronter la mort ?, Paris, Bayard, 2005, 96 p.] Frontières, 18(2), 79-80.

https://doi.org/10.7202/1073232ar

Ce document est protégé par la loi sur le droit d'auteur. L'utilisation des services d'Érudit (y compris la reproduction) est assujettie à sa politique d'utilisation que vous pouvez consulter en ligne.

https://apropos.erudit.org/fr/usagers/politique-dutilisation/
Cet article est diffusé et préservé par Érudit.

Érudit est un consortium interuniversitaire sans but lucratif composé de l’Université de Montréal, l’Université Laval et l’Université du Québec à Montréal. Il a pour mission la promotion et la valorisation de la recherche. https://www.erudit.org/fr/ 
tre, elle passe en revue les quatre principales tentatives qui ont été utilisées au cours de l'histoire pour surmonter la mort: les récits mythologiques, les croyances religieuses, les hypothèses métaphysiques et les utopies scientifiques. Comme aucune de ces hypothèses n'a réussi à faire disparaître en l'être humain l'angoisse qu'il éprouve devant la perspective de son propre anéantissement, il a dû faire appel à diverses ruses pour tenter de neutraliser la mort.

L'analyse de ces ruses constitue le sujet du deuxième chapitre. La transmission de ses gènes et de ses œuvres sont les deux stratagèmes les plus anciens et les plus universels, qui donnent l'illusion de tenir la mort à distance. Dastur présente évidemment des stratégies plus inquiétantes, au moyen desquelles les êtres humains cherchent l'immortalité. Le clonage, dont on ne peut s'empêcher de croire qu'il sera tôt ou tard appliqué aux êtres humains, est l'une d'entre elles. Pourtant, force est de reconnaître avec l'auteure qu'il ne sera jamais possible d'assurer l'immortalité, puisque ce qui différencie un individu et son clone, c'est précisément leur place dans le temps et dans le monde social qui façonne tout autant les individus que leur origine biologique. En attendant que le clonage humain puisse se réaliser, les individus recourent à différentes astuces pour tenter de réaliser le fantasme de l'éternelle jeunesse. Dastur signale la pharmacopée, la chirurgie esthétique et le body building. Dans nos sociétés obsédées par le souci de la sécurité, elle n'oublie pas de mentionner les sports extrêmes, car ils apparaissent, eux aussi, comme des manœuvres pour échapper à la mort. En effet, ces conduites à risques qui flirtent avec la mort ne s'accompagnent-elles pas d'un sentiment de toute-puissance qui est à l'opposé d'une véritable assomption de la finitude? Dastur estime que le suicide est également une ultime parade contre la mort, car celui qui choisit de se suicider refuse que la mort lui vienne sans qu'il y soit pour rien, qu'elle le frappe comme une fatalité. Une autre manière de se donner l'illusion d'être immortel c'est de devenir, dans la célébrité, le point de convergence de tous les regards. Il ne s'agit pas tant du désir d'inscrire son nom dans I'histoire ou de créer des œuvres susceptibles de passer à la postérité, mais de la tentative de trouver une consolation ou un remède immédiat à son mal d'être en demandant à autru l'attestation de sa propre existence.
Comme le dit si bien l'auteure, ce qui est recherché dans la célébrité, c'est «l'objectivation de soi, I'identification de son être à son image publique, afin de se voir déchargé du fardeau de sa finitude» (p. 63).

Bien entendu, toutes ces tentatives de neutralisation de la mort se révèlent tôt ou tard illusoires et il y a toujours un moment où l'être humain se voit sommé d'assumer sa finitude. Mais que veut dire "assumer sa mort "? C'est à cette question que tente de répondre le troisième et dernier chapitre. Pour ce faire, Dastur montre d'abord que la réponse à cette question varie selon que l'on considère la mort comme le dernier épisode de la vie humaine ou au contraire comme l'attribut essentiel de celle-ci. Puis, elle ajoute que I'Occident nous propose deux grandes façons de se préparer à la mort: celle du christianisme et celle de la philosophie. Dans la tradition chrétienne, l'assomption de la mort aurait la forme, dialectique, d'une reconnaissance qui est en même temps déni. Quant à la philosophie, elle proposerait une manière plus sereine de se préparer à la mort. Pour nous en convaincre, Dastur nous présente brièvement, tour à tour, la pensée de quelques grands penseurs: Socrate, Épicure, Montaigne, Spinoza et Heidegger. L'auteure reconnaît toutefois que l'idée qu'on puisse se délivrer de l'angoisse d'être mortel en faisant appel à la raison constitue un leurre, aussi trompeur que les discours religieux ou technico-scientifiques. Selon elle, la seule façon d'affronter la mort est de cesser d'opposer de vaines résistances à l'angoisse, c'est de se laisser porter par elle, pour parvenir à atteindre ce moment où elle se changera en joie. Pour décrire un tel changement d'état, Dastur fait appel au grand mystique allemand du XIIIe-XIVe siècle, Maître Eckart, qui parlait à ce propos d'un laisser-être (Gelassenheit) qui rend toutes choses à elles-mêmes, du moment que I'on parvient à se dépouiller de son moi. Ce détachement, précise-t-elle, ne doit aucunement être identifié à l'ataraxie stoïcienne: c'est l'état de celui qui se sépare des craintes et des opinions communes, non dans le refus de sa propre finitude, mais afin de s'ouvrir à sa vérité. En définitive, l'idéal serait non pas seulement affronter la mort et voir en elle une imperfection, mais pouvoir mourir en voyant là une capacité de l'être humain. C'est à partir de là, conclut Dastur, "que pourrait alors être révélé à l'être humain que l'angoisse de la mort 
n'est nullement incompatible avec la joie d'exister» (p. 94).

La lecture de ce beau petit livre sera pleine d'intérêt pour ceux et celles qui désirent s'interroger de manière critique sur la façon dont on peut vivre la mort comme la marque de notre existence.

Jean-Jacques Lavoie 